\title{
Mobile application to improve reading habits using Virtual Reality
}

\author{
Estefany Chavez-Helaconde, Israel Pancca-Mamani, Julio Vera- \\ Sancho, Betsy Cisneros-Chavez, Wilber Valdez-Aguilar \\ Universidad Nacional de San Agustín de Arequipa \\ Email: \{echavezhe,ccondorimama,ipancca,jveras,bcisnerosc,wvaldez\}@unsa.edu.pe
}

\begin{abstract}
Education is changing rapidly, so emerging technologies are being used to improve this process. One of these technologies is the Virtual Reality (VR), whose field of action is increasingly broad, so it has been incorporating new methods in teaching having a great positive impact in recent years, but the applicability in the area of communication is minimal. Seeing the challenges faced by the Ministry of Education in the development of reading skills and strengthening the capabilities of students in our country. In the this research a new alternative is proposed, to improve the beginnings of the habit of reading in students of second grade of Elementary School having to use of a mobile application with VR named Diverticuentos that generates scenes of the readings in 360 o besides being con-nected to a databases like firebase that allows us to see the progress of each stu-dent verifying that it is possible to integrate this new technology in the sessions and to generate a beginning of habit of reading of the students.
\end{abstract}

Keywords: Virtual reality, Reading habits, M-Learning, Unity.

DOI: $10.37789 /$ ijusi.2020.13.1.3

\section{Introduction}

In this research, we propose to improve the beginnings of reading habits in second graders of Elementary School, through the use of educational software that helps students to be motivated and read with pleasure and enthusiasm (Tondeur et al., 2017)

The educational system has been incorporating new tools that bring students closer to new knowledge in a dynamic and interactive way. However, the knowledge and applicability of this digital tool in reading habits is still emerging in the field of teaching (Howard, 2018).

In 2018, the Ministry of Education carried out an evaluation in the area of 
communication for the second grade of Elementary School. The results in reading were evaluated according to the performance at different levels of achievement, which were initiated, in process, and satisfactory. These data show us the levels of achievement and percentages. Compared to 2016 and 2018 , there was no significant progress. In the reading tests conducted in $2016,6.3 \%$ of students were at the beginning of learning achievement, $47.3 \%$ were in progress, and $46.4 \%$ were satisfactory. In 2018 , reading test results showed $5.8 \%$ of students were at the beginning of learning achievement, $56.4 \%$ were in progress, and $37.8 \%$ were satisfactory. Therefore, it is important for teachers to provide opportunities for students to read different types of texts and reading genders (MINEDU, 2016).

\section{Related Work}

Ariston Harianto in his research "Strengthening the reading habits of young people through text-based games Reinforcing youth reading habits through text-based games", which will improve the reading habits of participants. The game has a good story, interesting enough for the player to immerse himself in the game and therefore want to explore and discover more. The design to complete the game has multiple paths, each path is totally different from the other, therefore, the user experience is different. The experience of a different story and options motivates them more to keep reading and concluding the text. It is concluded that text-based games can have a significant impact as a means of learning and directly improve reading habits among young people (Harianto et al, 2015).

Pei-Luen Patrick Rau in his research "Speed reading on virtual reality and augmented reality" proposes that the reading performance in Virtual Reality (VR) and Augmented Reality (AR) can be different from that of a traditional desktop screen, because the reading and the performance generally depends on the device that displays the texts, in its research concludes that answering multiple choice questions in Virtual Reality (VR) and Augmented Reality (AR) is approximately $10 \%$ longer than in LCD, so, for example, teachers should give students $10 \%$ more time if they are given tests or other word processing tasks through virtual reality (VR) or augmented reality (AR) (Rau et al., 2018).

According to the authors Lamas, Loizides, Nacke, Petrie, Winckler and Zaphiris in their research "Using virtual reality to enable individuals with 
severe visual disabilities to read books" they present us with a main platform compatible with virtual reality, along with the programming language. The goal is to enable the application to read standard UTF-8 formats and translate them into a virtual reading panel for users to make their own reading settings. This common format allows greater compatibility with most texts and books. For our tests we use the Project, which is displayed in front of the user through a floating panel in a dark screen environment. Graphic distractions are kept to a minimum to avoid accessibility. Using the touch of the Oculus drivers to simulate virtual hands, the user can freely pick up a panel with lines. The user is shown 5 lines of text from the chosen book, which is adjustable. The user manipulates the environmental variables through voice control, which allows him to change the letter number in this virtual world (Weir et al., 2019).

\section{Related Work}

\subsection{Virtual Reality}

The term Virtual Reality (VR) is associated with images found in three dimensions generated by a computer and the interaction of users with this graphic environment (Ambrosio, 2018). This implies the existence of a complex electronic system to project visual spaces in 3D and send and receive signals with information about the user's performance, who with such a system can feel that he is immersed in a virtual world (Obrist \& Jara, 2015).

We also found that virtual reality is a technology that allows users to interact with virtual environments, simulated by a computer or a mobile device. In general, the virtual reality environment presents a visual experience on a stereo device screen (Maulana \& Khansa, 2019).

A virtual reality system can be considered an interface that is capable of creating a simulation involving all the senses, generated by a computer, that can be explored, visualized and manipulated in real time in the form of digital images and sounds, giving the sensation of presence in the computer environment (Avendaño Rodríguez \& Hernández Perilla, 2018)

\subsection{Reading habit}

The reader's habit is to promote and propagate the repetitive activity of 
reading until it becomes an intrinsic and natural need, using various existing or innovative mechanisms or strategies (Vivanco, 2018).

It is advisable to create this habit and the reader's sensitivity through imagination, which causes a better connection with the text, which characterizes the act of reading. The pleasure produced by aesthetic values generates motivates and captures the interest in reading (Vilota et al, 2015).

For the formation of a reading habit, motivations are necessary to guide the taste for reading. Habits are formed by the conscious repetition of a series of activities and by adaptation to certain circumstances. It is a way of being acquired progressively through learning (Alvarez et al., 2020). Therefore, an average of more than two months is calculated to generate a new behavior that becomes automatic, to be exact 66 days and, in addition, can vary widely depending on the behavior of the person and the circumstances so indicates Phillippa Lally (2020).

\section{Materials and methods}

For the implementation of the application we use the following platforms and ser-vices:

- Unity: Unity3D is a cross-platform integrated game development tool developed by Unity Technologies that allows players to easily create interactive content such as 3D video games, building visualizations, real-time 3D animations, etc(Uniti.com, 2019)

- Fungus: Is a free open source project, used to create 2D and 3D narrative games(Fungus, 2019)

- GVR unity Sdk: It is a package used to create virtual reality environments.

- Rest Client for Unity Api: This api supports HTTP methods that are required for the Firebase real-time connection. (Client, 2019)

- Firebase: Is an API for saving and synchronizing data in the cloud in real time. (Albertengo et al.)

- Google Analytics: Taking advantage of the fact that we are using Firebase, Google Analytics is an analytical tool that analyzes the behavior of users when they enter the application, either web or app, this web analyzer provides simple statistics and simple on the website (number of visitors, average number of visits to the app per visitor, average duration of the app). (Sharma) 


\section{Proposal}

The architecture of our application with Firebase is shown in Fig. 1. For the connec-tion and we use API rest client that has the purpose of doing the Login / Register and saving the 2D and 3D scores.

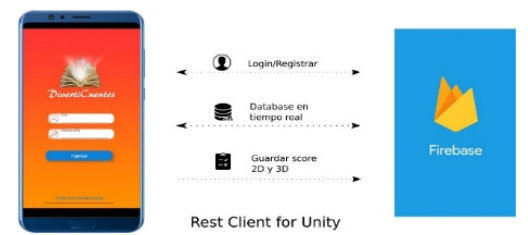

Figure. 1. Application architecture.

To save the user process view of Login, Register, Save score 2D and 3D we take in-to account the following data:

- Register: We request the following information: ID, First and Last Name, Pass-word, Grade and Section.

- Login: The ID and password are required.

- Save score 2D: To save the user process in 2D mode, we save the following data:

- Date: It is the date and time that the reading finished.

- idUser: user ID

- score: Score made in the questionnaire.

- timeQuest: Time to answer the questionnaire.

- timeRead: Time to read the reading.

- Save 3D score:

- Date: It is the date and time that your virtual questionnaire ended.

- idUser: user ID

- score: Score made in the questionnaire.

- timeQuest: Time to answer the virtual questionnaire. 


\subsection{Application Usage}

For the use of the application, it is necessary for the mobile device to be midrange and the screen is enlarged so that the user, when using the cardboard, has a wide view in the virtual environment, for the tests we use a Huawei P30 and a cardboard VR-BOX. The Fig. 2 shows the simulation in virtual and external mode, showing the representation of the $\mathrm{X}, \mathrm{Y}$ and $\mathrm{Z}$ axes. The user will be able to move within the virtual environment by tilting his head down in the direction he is seeing in the virtual environment.

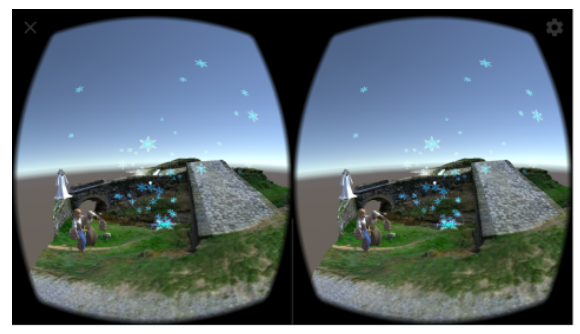

(a)

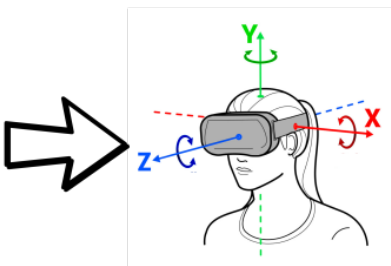

(b)

Figure. 2. (a). Virtual panorama, (b) External panorama of the 3 dimensions

The Figs. 3,4 and 5 are the views for 2D mode.

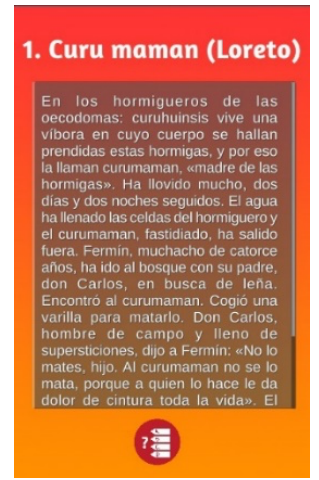

Figure. 3. Reading.
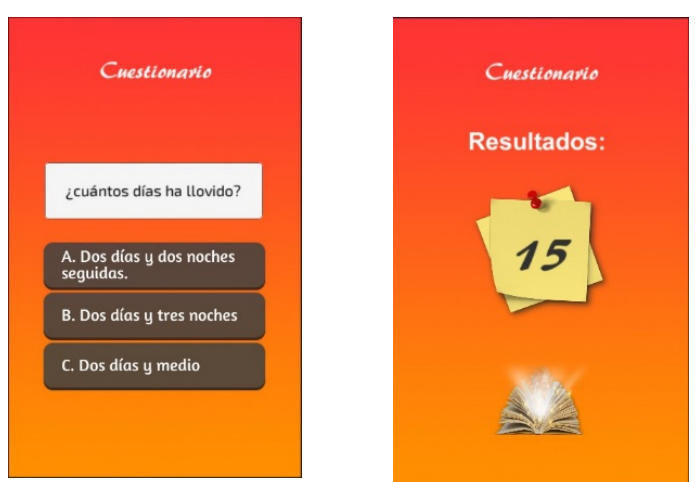

Figure. 4. questionnaire. Figure. 5. Outcome. 


\section{Methodology}

The methodology used in the research is of an applicative nature, being a demonstrative explanatory research.

The design of the research will be pre-experimental because we will have an experimental group, the results will be measured in time, the technique used to collect the information will be through a questionnaire applied before and after the use of the app. A quantitative data analysis technique was used because we used statistical techniques for the representation of the results having as hypothesis "The use of virtual reality improves the reading habits in second grade students of the San Francisco de Sales Private Educational Institution". In the study, 25 students of 2 nd grade of primary school with an average age of 7 to 8 years participated in the application of the instrument during the second two-month period in the months of August and September with a pre-test and a post-test that obtained results that were codified to obtain the statistical data. In the learning sessions, literal questions were also asked in the app in order to verify that each student carried out the readings.

\subsection{Pre-evaluation}

In this first stage, a questionnaire was taken from second grade students in Regular Basic Education (EBR), to measure their frequency, time and consistency in reading before applying the activities and use of the Funny Stories application. The question-naire is divided into three dimensions: desire, which consists of 10 items; knowledge, which consists of 12 items; and ability, which consists of 8 items. These are based on the dimensions proposed by the author Covey Salazar Bustamante, who defines habit as an intersection of knowledge (what to do? / why?); ability (how?) and desire (mo-tivation / wanting to do). (Salzar, 2006)

\subsection{Selection of reading}

The selection of readings is defined according to the contents that are worked in the area of communication, according to the Ministry of Education where narrative read-ings were selected that include: stories, fables, myths and legends; it was considered pertinent to select the legends of Peru to revalue our oral customs and traditions, using the competence "Read various types of texts in your mother tongue", in this way the student will give his opinion and 
recommend readings according to his interest, enjoy-ing his readings as a main objective and generating the beginning of a reading habit. The selected readings are the following:

As shown in Table 1, the readings that were selected to be taken to virtual reality are shown:

Table 1. Readings

\begin{tabular}{|l|l|l|}
\hline 3d Reading & Time & Genre \\
\hline El Puente del diablo & $17 \mathrm{~min}$ & Narrative \\
\hline El tuturutu & $17 \mathrm{~min}$ & Narrative \\
\hline $\begin{array}{l}\text { La leyenda de la casa } \\
\text { embrujada }\end{array}$ & $17 \mathrm{~min}$ & Narrative \\
\hline $\begin{array}{l}\text { La sirena del Puente de } \\
\text { fierro }\end{array}$ & $17 \mathrm{~min}$ & Narrative \\
\hline Duendes arequipeños & $17 \mathrm{~min}$ & Narrative \\
\hline $\begin{array}{l}\text { Los Subterráneos de la } \\
\text { Catedral }\end{array}$ & $17 \mathrm{~min}$ & Narrative \\
\hline
\end{tabular}

\subsection{Selection of the models}

After selecting the readings, we look for $3 \mathrm{D}$ models that resemble the characters in the texts, using free model download platforms such as mixao, free $3 \mathrm{~d}$, some models bought in unity $3 \mathrm{D}$ and sketchfab. The selected models have animation and move-ment, so the scenes shown are more interactive, users can walk and visualize the characters in movement and feel the immersion in 360 in all the scenes shown with the VR viewer.

\subsection{Application Description}

The mobile application called "Diverticuentos", has as main objective to generate the beginnings of the reading habit in second grade students, using the application to have a selection of 7 stories in $3 \mathrm{D}$ with VR and 20 stories in $2 \mathrm{D}$.

The students can access the application through a smartphone that uses the An-droid operating system.

The functionality of the mobile application "Diverticuentos" is done through a reg-ister that stores the information constantly, this way there will be a register of entry and exit of the APP in real time. Users must register, completing their name and sur-name, grade they belong to, ID number and password. To enter the application, their user name and password will be 
placed by accessing a general 2D AND 3D history screen. The 3D stories will be used in the classroom along with the learning sessions and the 2D stories will be done at home, using the APP and the Internet. Each learn-ing session that was done at the school with VR was in a time of 17 minutes for each session done. Each student will have a database that will be monitored showing the progress that each student, during the use of the application, for both $2 \mathrm{D}$ and $3 \mathrm{D}$ readings. At the end of the reading of each learning session, the student will be able to visualize some scenes of the texts, then he/she will have to answer 3 to 4 questions of literal level to corroborate that the student carried out the reading. Finally, they will have a satisfaction question for each reading done. The information obtained was used to analyze the time of use of the application and the time it took for each read-ing.

The table 2 of events and parameters is shown:

\begin{tabular}{|l|l|}
\multicolumn{2}{|c}{ Table 2. Events and parameters. } \\
\hline Events & Parameters \\
\hline Start of the game & Start of the game \\
\hline Game completed & $\begin{array}{l}\text { Saved score, type of reading (2D or } \\
\text { 3D) }\end{array}$ \\
\hline Reading in the app & Reading time \\
\hline $\begin{array}{l}\text { Reading } \\
\text { questionnaire }\end{array}$ & Time to answer the reading \\
\hline
\end{tabular}

\subsection{Learning session}

The learning sessions were carried out respecting the structure and the moments of each session according to the communication area, before, during and after the reading. The sessions carried out had two pedagogical hours of dictation per session, using VR for 17 minutes twice a week in which characters and the place where the stories were developed were visualized, all of them with VR. At the beginning of the reading ses-sion, the students were asked if they knew any of the characters they had seen. What will happen to the characters? They knew the purpose of the session "Today we will know the legend of the Bolognesi Bridge".

As in the beginning of the session the students visualized the characters in 3D with VR and contextualized the scenes and characters so they could answer the questions, during the reading all the students were asked to do a silent reading as well as a choral reading, after the reading we verified that the questions were correct from the begin-ning of the learning session by also 
asking some additional questions such as what new things did they find? what was the text about? As feedback we used the app "Fun-ny Stories" to verify if the reading was done through 3 literal questions, to end the ses-sion we asked the following questions: What did we learn today? Did we like the topic what we worked on? The sessions were held over a month and a half.

\section{Results}

The research was carried out with a population of 25 students of 12 girls and 13 boys of second grade of primary school of regular basic education (EBR), between the ages of 7 and 8 years. Obtaining the results that support the hypothesis the students was con-sidered to compare the results of the pre-test and post- test the two-dimensional longi-tudinal perimeter test was considered because the samples are related to the same experimental group.

Obtaining the results which show that the levels of reading habits in the post-test are better than in the pre-test, we proceeded to contrast, to know if they have signifi-cant differences:

H0: The use of virtual reality does not improve reading habits in second grade stu-dents of the San Francisco de Sales Private Educational Institution.

H1: The use of virtual reality improves reading habits in second grade students of the San Francisco de Sales Private Educational Institution.

\subsection{Results of the dimension:}

Table 3. Results of the desire dimension.

\begin{tabular}{|l|r|r|r|r|}
\hline \multirow{2}{*}{} & \multicolumn{2}{|c|}{ Pre test } & \multicolumn{2}{c|}{ Post test } \\
\cline { 2 - 5 } & f & $\%$ & f & $\%$ \\
\hline very high & 0 & $0.00 \%$ & 0 & $0.00 \%$ \\
\hline high & 5 & $20.00 \%$ & 14 & $56.00 \%$ \\
\hline low & 14 & $56.00 \%$ & 11 & $44.00 \%$ \\
\hline very low & 6 & $24.00 \%$ & 0 & $0.00 \%$ \\
\hline Total & 25 & $100.00 \%$ & 25 & $100.00 \%$ \\
\hline
\end{tabular}

According to the Figure 6 and the Table 3 of the desire dimension in the pre-test, it is observed that $20.00 \%$ is in the high level, $56.00 \%$ are in the low level and $24 \%$ was found; in the post-test it is observed that the $56.00 \%$ is at the high level, $44.00 \%$ is at the low level. It is observed that in the two tests nobody is at the very high level, it is evident that at the high level there 
is an improvement of $56.00 \%$.

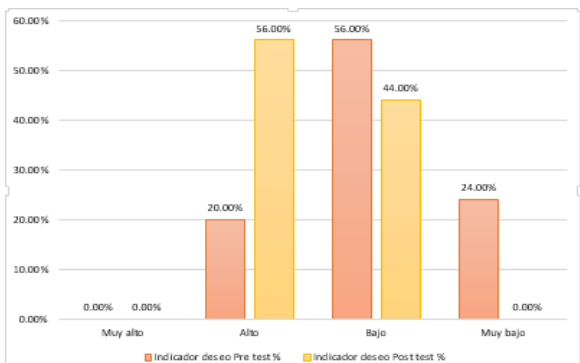

Figure. 6. Desire dimension results

\subsection{Results of the knowledge dimension:}

\begin{tabular}{|l|r|r|r|r|}
\hline \multirow{2}{*}{ Table 4. Results of the knowledge dimension } \\
\cline { 2 - 5 } & \multicolumn{1}{|c|}{ Pre test } & \multicolumn{2}{c|}{ Post test } \\
\cline { 2 - 5 } & $\mathbf{f}$ & $\mathbf{\%}$ & $\mathbf{f}$ & $\mathbf{\%}$ \\
\hline very high & 0 & $0.00 \%$ & 0 & $0.00 \%$ \\
\hline high & 6 & $24.00 \%$ & 24 & $96.00 \%$ \\
\hline low & 17 & $68.00 \%$ & 1 & $4.00 \%$ \\
\hline very low & 2 & $8.00 \%$ & 0 & $0.00 \%$ \\
\hline Total & 25 & $100.00 \%$ & 25 & $100.00 \%$ \\
\hline
\end{tabular}

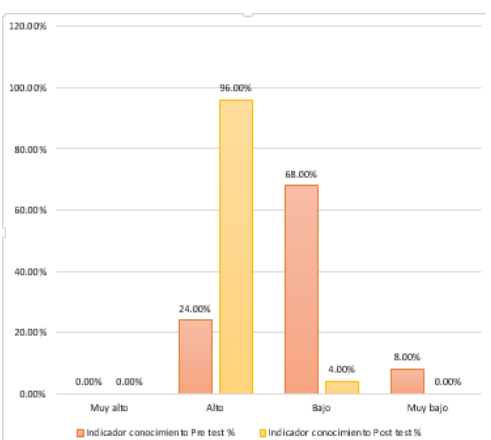

Figure. 7. Results of the knowledge dimension

According to the Figure 7 and the Table 4, From the knowledge dimension, in the pre-test, it is observed that $24.00 \%$ are at the high level, 
$68.00 \%$ are at the low level and $8.00 \%$ are at the very low level; in the posttest it is observed that $96.00 \%$ are at the high level, $4.00 \%$ are at the low level and none are at the low level.

It is observed that none is at the very high level in the pre-test and posttest.

\subsection{Results of the capacity dimension:}

Table 5. Results of the capacity dimension

\begin{tabular}{|l|r|r|r|r|}
\hline & \multicolumn{2}{|l|}{ Pre test } & \multicolumn{2}{l|}{ Post test } \\
\hline & f & $\%$ & f & \% \\
\hline very high & 1 & $4.00 \%$ & 1 & $4.00 \%$ \\
\hline high & 13 & $52.00 \%$ & 20 & $80.00 \%$ \\
\hline low & 7 & $28.00 \%$ & 4 & $16.00 \%$ \\
\hline very low & 4 & $16.00 \%$ & 0 & $0.00 \%$ \\
\hline Total & 25 & $100.00 \%$ & 25 & $100.00 \%$ \\
\hline
\end{tabular}

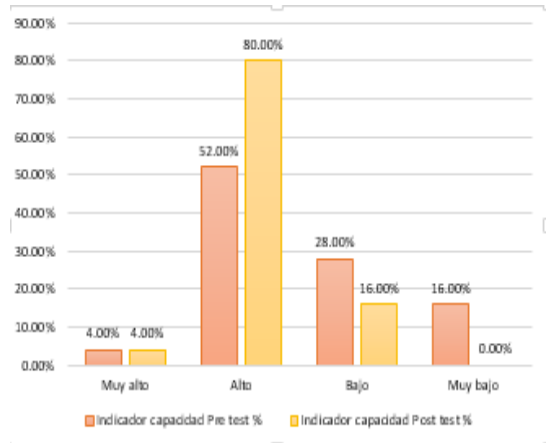

Fig. 8. Capacity dimension results

According to the figure 8 and the Table 5 From the capacity dimension, in the pre-test, it is observed that $52.00 \%$ are at the high level, $28.00 \%$ are at the low level and $16.00 \%$ are at the very low level; in the post-test it is observed that $4.00 \%$ are at the very high level, $80.00 \%$ are at the high level and $16.00 \%$ are at the low level.

It is observed that in the two tests that in the high level I improve by 4.00 $\%$ and in the high level I improve by $80.00 \%$ and nobody is in the very low level. 


\subsection{Results of the reading habit:}

Table 6. Reading habits results

\begin{tabular}{|l|r|r|r|r|}
\hline & \multicolumn{2}{|l|}{ Pre test } & \multicolumn{2}{l|}{ Post test } \\
\hline & $\mathbf{f}$ & $\mathbf{\%}$ & $\mathbf{f}$ & $\%$ \\
\hline very high & 0 & $0.0 \%$ & 0 & $0.0 \%$ \\
\hline high & 4 & $16.0 \%$ & 22 & $88.0 \%$ \\
\hline low & 19 & $76.0 \%$ & 3 & $12.0 \%$ \\
\hline very low & 2 & $8.0 \%$ & 0 & $0.0 \%$ \\
\hline Total & 25 & $100.0 \%$ & $100.00 \%$ & 25 \\
\hline
\end{tabular}

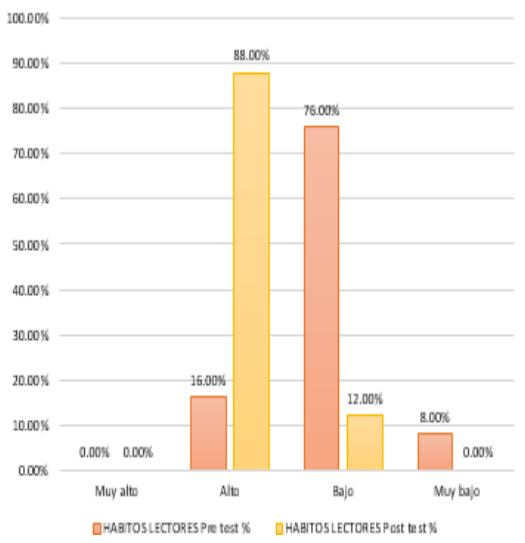

Figure. 9. Result of reading habit

Analyzing the entire questionnaire of the 25 students according to the Figure 9 and the Table 6 in the pre-test $16.00 \%$ is at the high level and 76.00 $\%$ is at the low level, for the post-test $88.00 \%$ rose to the high level and at the low level it was found at $12.0 \%$. No one was found at the very high and very low level.

The student's $t$ test was performed considering the confidence level of $95 \%$ and an error margin of $5 \%(0.05)$, as it is a variable of categorical origin, therefore the corre-sponding test was performed.

Calculate the p-value of the normality test To be able to apply the instrument, the alpha shapiro wilks statistical reliability test was performed, 
with our population being less than 30 students, which allows us to measure the normality test.

Thus, the data was submitted, as shown in the Tables 7,8 , the results being.

Table 7. Normality test

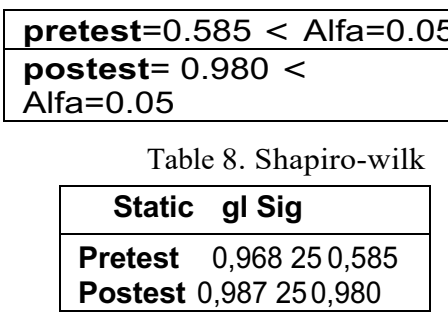

According to the table of paired differences, it is concluded that the normality test passed as shown in the Table 9 .

Table 9. Testing of paired samples

\begin{tabular}{|l|l|l|l|l|l|l|l|}
\hline & & & \multicolumn{4}{|c|}{$\begin{array}{l}\text { 95\% confidence interval of the } \\
\text { difference }\end{array}$} \\
\cline { 2 - 7 } & Average & Desviation & $\begin{array}{l}\text { Error } \\
\text { Average }\end{array}$ & Lower & Higher & T & gl Bilateral \\
\hline $\begin{array}{l}\text { par 1 } \\
\text { prestest } \\
\text { posttest }\end{array}$ & $-0,50333$ & 0,22339 & $100.00 \%$ & $-0,59554$ & $-0,41112$ & $-11,266$ & 240,000 \\
\hline
\end{tabular}

Decision of the statistical test As p-value $=0.000$ alpha $=0.05 \mathrm{H} 0$ is rejected and $\mathrm{H} 1$ is accepted Conclusion: There is a significant difference in the mean before and after the learning sessions which were based on virtual environments.

The $\mathrm{t}$-studen tests will be carried out for paired samples as observed in the Table 10.

Table 10. Paired Sample Statistics

\begin{tabular}{|l|l|l|l|l|l|}
\hline & & average & $\mathrm{N}$ & Desv. & Desviation \\
\hline & & & & Deviation & average error \\
\hline $2 *$ Par 1 & pre-test & 2,2650 & 25 & 0,32137 & 0,06427 \\
\hline & pos-test & 2,7683 & 25 & 250,21384 & 0,04277 \\
\hline
\end{tabular}

In fact, students increased their reading habit average from 2.26 (AV) to 2.76 (CS). 


\section{Conclusions}

In this research, a significant difference was presented in the beginnings of the read-ing habit in the students before and after using the application with virtual reality. Therefore, it is concluded that virtual reality has significant effects, in the pre-test it was found in $16.00 \%$ the high level and $76.00 \%$ the low level, for the post-test $88.00 \%$ went up to the high level and in the low level it was found in $12,0 \%$. No one was found at the very high and very low level.

It has been verified how the sessions carried out in the students, have contributed in the beginnings of the reading habits also in the attraction to read and to finish each one of them motivating them to read more. It also generates interactivity, motivation and interest of the students in the readings. We must not forget that technology is a support for student learning that must be used effectively and usefully in the class-room. In this way, technology will have a positive impact on student learning by be-ing interactive and motivating.

\section{Acknowledgment}

A special recognition to the Universidad Nacional de San Agustín de Arequipa, UNSA that through the contract of subsidy IAI-005-2018-UNSA of the project "Animaci' on a la lectura con M-Learning, creando situaciones reales y virtuales", is that it was possible to make the investigation of the proposal presented in this article

\section{References}

Jo Tondeur, Johan van Braak, P.A.E.A.O.L.: Understanding the relationship be- tween teachers' pedagogical beliefs and technology use in education: a systematic review of qualitative evidence. Educational Technology Research and Development 65(555) (2017). https://doi.org/10.1007/s11423-016-9481-2

Howard, Sarah, S.K..L.K.: Virtual reality content for higher education curriculum. Virtual reality content for higher education curriculum (2018) https://eprints.qut.edu.au/116132/

MINEDU: Resultados de la evaluación censal de estudiantes 2016. "http://umc.minedu.gob.pe/resultadosece2016/" (2017)

Harianto, A., Nugroho, E., Fredericco, R.: Reinforcing youth reading habits through text- 
based games. In: 2015 4th International Conference on Interactive Digital Media (ICIDM), IEEE (2015) 1-5 doi: 10.1109/IDM.2015.7516344

Rau, P.L.P., Zheng, J., Guo, Z., Li, J.: Speed reading on virtual reality and augmented reality. Computers \& Education 125 (2018) 240-245 https://doi.org/10.1016/j.compedu.2018.06.016

Weir, K., Loizides, F., Nahar, V., Aggoun, A.: Using virtual reality to enable individuals with severe visual disabilities to read books. In: IFIP Conference on Human-Computer Interaction, Springer (2019) 680-684 https://doi.org/10.1007/978-3-030-29390-1_62

Ambrosio, A. P. Una aposta pel canvi en les sèries de ficció. La realitat virtual com a estratègia narrativa al servei de la immersió de l'espectador. Anàlisi: quaderns de comunicació i cultura, (57), 1-14. (2017) https://doi.org/10.5565/rev/analisi.3105

Obrist Bertrand, V. U., \& Martínez Jara, E. A. (2015). Application of virtual reality in a learning experience. Congreso Argentino de Ciencias de la Computación (Junín, 2015).

Maulana, H., Khansa, R.: Virtual reality application for educational interactive media "3 historical monuments of yogyakarta". In: Journal of Physics: Conference Series. Volume 1193., IOP Publishing (2019) https://doi.org/10.1088/1742-6596/1193/1/012019

Avendaño Rodríguez, L.A., Hernández Perilla, J.M.: Comunicación y experiencia mediada por la realidad virtual. Nexus (1900-9909) (24) (2018) doi.org/10.25100/nc.v0i24.7693

Vivanco Tinco, M.C.: Aplicación del plan lector para fomentar el hábito lector en los estudiantes del tercer grado de primaria de la IEP "Fraternidad universal" del distrito de ate-2017. (2018) http://repositorio.unfv.edu.pe/handle/UNFV/2604

Villota, M.F.E., Escobar, M.F., Velásquez, F.G.: Una revisión general a los hábitos y técnicas de estudio en el ámbito universitario. Psicogente 18(33) (2015) 166-187

http://doi.org/10.17081/psico.18.33.64

Álvarez Martínez-Iglesias, J. M., Rabal Alonso, J. M., \& Molina Saorín, J. (2020, March). Unidades didácticas de lengua y literatura basadas en las TIC. In Congreso Internacional de Investigación e innovación en educación infantil y primaria..

Lally, P., Van Jaarsveld, C. H., Potts, H. W., \& Wardle, J. (2010). How are habits formed: Modelling habit formation in the real world. European journal of social psychology, 40(6), 998-1009. https://doi.org/10.1002/ejsp.674

Unity.com: Documentacion de unity. urlhttps://unity3d.com/es/unity (2019)

Fungus: Documentacion de fungus. urlhttp://fungusgames.com/ (2019)

Client, R.: Documentación de rest client. url- https://assetstore.unity.com/packages/ tools/network/rest-client-for-unity-102501 (2019)

Albertengo, Guido y Debele, F.G.y.H.W.y.S.D.: Sobre el rendimiento de los servicios web, la mensajería en la nube de google y la mensajería en la nube de firebase URI: http://hdl.handle.net/10486/688897

Sharma, Manu y Joshi, S.: Publicidad en línea con software de análisis web: una comparación con el método ahp. International Journal of Business Analytics (IJBAN)

Salazar Ayllon, S.: Claves para pensar la formación del hábito lector. Allpanchis (66) (2006) 13-46. 